\title{
IMPACT OF OPENNESS TO EXPERIENCE ON KNOWLEDGE SHARING UNDER THE MEDIATING EFFECT OF INTENTION TO SHARE KNOWLEDGE AND MODERATING ROLE OF INTERPERSONAL TRUST
}

\author{
KAMRAN ANWAR \\ Capital University of Science and Technology, Islamabad, Pakistan
}

\begin{abstract}
The purpose of the study was to test the relationship between openness to experience and knowledge sharing under the mediating effect of intention to share knowledge and moderating effects of interpersonal trust. The data were collected from employees working in the public sector in Pakistan, with the sample size of 185 . The results indicated that openness to experience significantly and positively predict knowledge sharing among employees, although the results showed that intention to share the knowledge does not mediate the relationship between the two. Similarly, as per findings, interpersonal trust failed to moderate the relationship between intention to share knowledge and knowledge sharing. Implications of the study are also discussed which provide a way forward to decision makers in the organizations in finding how to use knowledge sharing in the contextual settings of Pakistan.
\end{abstract}

\section{INTRODUCTION}

Now-a-days, knowledge is considered as a leading resource of any organization. Such importance is derived from the fact that knowledge is the key antecedent for creativity and ongoing innovation in any organization. Through effective utilization of knowledge, an organization may achieve sustainable competitive advantage (Foss \& Pedersen, 2002). Hence, managing knowledge demands due consideration to ensure desired organizational performance.

Knowledge sharing is among key elements of knowledge management. It has become necessity of every organization owing to its broad utility (Asrar-ulHaq, Anwar, \& Nisar, 2016). According to Witherspoon, Bergner, Cockrell, and Stone (2013), knowledge sharing is a building block for the success of the organization and it is being adopted as a survival strategy. Knowledge sharing in teams has been found to lead to superior team performance(Srivastava et al., 2006). Knowledge sharing actually entails set of behaviors necessary for exchange of knowledge in possession. This activity transforms individual knowledge into organizational knowledge (Li, Montazemi, \& Yuan, 2006). Sharing knowledge helps in developing healthy learning environment within the organization.

Knowledge sharing behaviors are likely to be influenced not only by personal motivations but also by contextual forces (Yoo \& Torrey, 2002). For example, personal characteristics of the individual including age and gender tend to influence the individuals' knowledgesharing behavior. Similarly, few innate qualities of the individuals and relative attitude are important antecedents of knowledge sharing behavior (Wasko \& Faraj, 2005). Furthermore, organizational behavior supports the tendency towards knowledge sharing (Bordia, Irmer \& Abusah, 2006). According to Baker, Leenders, Gabbay, Kratzer, and Van Engelen (2006), characteristics and norms of a team tend to influence the knowledge sharing behavior.

Previous studies show a significant work on different antecedents which play role in knowledge sharing. However, there has been dearth of literature regarding an important dispositional quality of the employee i.e. openness to experience and its relative impact on knowledge sharing (Cabrera et al., 2006). Openness to experience is linked to active imagination, aesthetic sensitivity, attentiveness to inner feelings, and preference for variety, intellectual curiosity, originality and independence of judgment. Individuals with high levels of openness are curious about both inner and outer worlds and are willing to consider new ideas and unconventional values, and they experience both positive and negative emotions more keenly than individuals who score low on openness (Matzler, Renzl, Müller, Herting, \& Mooradian, 2008). Previous studies also lack focus on mediating effect of intention to share knowledge. In fact, any dispositional traits or organizational behaviors primarily induce intention towards knowledge exchange among employees. This intention then prepares the 
employees to transfer the knowledge whether tacit or explicit to the peers. Thus, this intermediary aspect needs due attention for exploration.

Besides individual trait, interpersonal trust is another important factor that may strengthen the relationship between openness to experience and knowledge sharing. Interpersonal trust is the willingness of a party to be vulnerable (Abrams, Cross, Lesser, \& Levin, 2003). Apparently, it may enable knowledge bearer to expose his knowledge to others. Trust is the fundamental factor in knowledge sharing between parties (Mayer, R.C., Davis, J.H., \& Schoorman, 1995; Butler, 2001). Trust, because it underpins a willingness to communicate, is also critical for knowledge sharing in teams (Mooradian et al., 2006). However, exact mechanism through which interpersonal trust can boost aforesaid relationship still remains intact. This study will cover the details about how trust can play role in augmenting the intention to share knowledge.

\section{LITERATURE REVIEW}

\section{Openness to experience and knowledge sharing}

Openness is one of the five personality factors from the FFM that has been replicated across Cultures (Cheung et al., 2008). It is the broadest personality domain of the Big Five, including a mix of traits relating to intellectual curiosity, intellectual interests, perceived intelligence, imagination, creativity, artistic and aesthetic interests, emotional and fantasy richness, and unconventionality (Silvia, Nusbaum, Berg, Martin, \& O'Connor, 2009; Silvia et al., 2008). According to Costa and Mc-Crae (1987), openness to experience refers to an individual's willingness to explore, tolerate, and consider new and unfamiliar ideas and experiences. Costa and Mc-Crae (1992) further distinguished among six facets of openness to experience, three of which are important in terms of reactions to dissimilarities: ideas (e.g., intellectual curiosity and open-mindedness), actions (e.g., being adaptable, valuing experimentation, and liking novelty), and values (e.g., fluid political and religious beliefs).

People who score high on openness to experience tend to be less dogmatic in their ideas, more willing to consider different opinions, more open to all kinds of situations, and less likely to deny conflicts than people who score low on openness to experience (Costa \& McCrae, 1992; LePine, 2003; McCrae, 1987). All these aspects of openness to experience are closely related to the essence of working in a diverse team, as members of diverse teams are more likely to have different viewpoints, attitudes, and ideas (and therefore conflict) than members of homogeneous teams (Cox etal., 1991; van Knippenberg et al., 2004). While working in diverse teams, members avail numerous opportunities to share/exchange their ideas, views and knowledge in possession.

Among other processes of knowledge management, knowledge sharing (K_SHARNG) has been identified as the most vital one. As identified by Witherspoon, Bergner, Cockrell, and Stone (2013), knowledge sharing is a building block for the success of the organization and it is being adopted as a survival strategy. Knowledge sharing is defined as the degree to which one actually shares one's knowledge with others across an organization. It refers to the provision of task information, know-how, and feedback regarding a product or procedure through both verbal and nonverbal communication (Shim, 2010).

There are a number of reasons why knowledge sharing is important to organizations (McNeish \& Mann, 2010). These include improvements to the "alignment to missions, vision and values, and strategy, joint team accountability, process focus, stronger awareness of customer and competition, a collaborative team environment, and decentralized decision making but consistent with corporate direction" (Tiwana, 2002). Knowledge sharing also reduces time to market new products through improved group processes (Cooper, 2001). Knowledge sharing is critical, as it can contribute to knowledge application, innovation, and ultimately an organization's competitive advantage (e.g., Jackson, Chuang, Harden, Jiang, \& Joseph, 2006).

Knowledge sharing is crucial because it enables people to capitalize on existing knowledge bases residing within and outside the organization, thus enhancing their capacity to come up with creative solutions, and enabling their organizations to develop new platforms for the development and introduction of new products and services to the market (Carmeli, Gelbard, \& ReiterPalmon, 2013). Studies that evaluated the role of knowledge and information sharing and creativity have found that both internal and external knowledge sharing led to increased creativity and innovation (Hulsheger, Anderson, \& Salgado, 2009).

HR professionals have neglected knowledge sharing for many years; however, with the passage of time, particularly in 2000 , they came to realize the importance of knowledge management. Since then, knowledge management and its processes became the foci of HR field (Blankenship \& Ruona, 2009). Knowledge sharing can be defined as the transference of knowledge among individuals, groups, teams, departments, and organizations (Crossan, Lane, \& White, 1999; Ipe, 2003).

In the literature, knowledge sharing is used in two ways. For some authors, knowledge sharing is mainly seen as part of exploitation (e.g. McElroy, 2003) while others consider it part of the exploration phase (e.g. 
Swan et al., 1999). Exploitation refers to the processes where existing knowledge is captured, transferred, and deployed in other similar situations. Exploration, on the other hand, involves processes where knowledge is shared, synthesized and new knowledge is created (McElroy, 2003). However, there is a difference between knowledge sharing as part of knowledge exploration (production) and knowledge sharing as part of knowledge exploitation (integration). Knowledge sharing in order to integrate knowledge takes place from one actor to many others at once ("broadcasting"). Knowledge sharing as part of knowledge production takes place more in the form of discussions, working together to solve a problem: actors define the problem together; discuss options, share knowledge to find a solution together. Within this view, knowledge sharing is not as wide and random as in the previous view, but more focused and structured.

Openness to experience drives towards enhanced imagination, considerations for internal feelings, variety seeking and appealing compassion. People scoring high on openness are often more curious about internal as well as external environments and ready to consider new ideas and unconventional values. Such people always experience every sort of feelings more deeply than individuals scoring low on openness to experience (Costa \& McCrae, 1992). In addition, highly open people prefer intellectual curiosity, creativity, flexible thinking, and culture and thereby try to develop more positive attitudes towards new learning experience.

Cabrera, Collins, and Selgado (2006) discovered that openness is a strong predictor of knowledge sharing because openness to experience is a reflection of a person's curiosity and originality which in turn are predictors of seeking other people's insights. Therefore, it can be anticipated that open individuals develop more expertise. As Constant, Sproull, and Kiesler (1996) proposed, individuals with higher levels of expertise are more likely to give useful advice; and less likely to contribute when they consider their expertise to be inadequate (Wasko \& Faraj, 2000, 2005). People high with openness score are more engaged in contributing and seeking knowledge. Thus, hypothesis one was developed:

Hypothesis 1. Openness to experience is positively related to knowledge sharing.

\section{Mediating role of intention to share knowledge on relationship between openness to experience and knowledge sharing}

According to Fishbein and Ajzen (1975), intention is assumed to capture the motivational factors that influence behaviors; it is an indication of an individual's willingness and readiness to behave. Thus, an individual's intention to share knowledge (INT_SK) highly determines his/her behavior to actually share knowledge with others. Research has shown that the best way to predict whether an individual will perform a specific behavior is by asking the simple question of if he/she intends to perform that behavior (Alajmi, 2011).

According to the Theory of Reasoned Actions, personality traits are exogenous factors essential for explaining individual behaviors and egoism is a factor influencing attitude. In the field of trait studies, scholars have reported that a relatively stable and consistent relationship exists between organization members' personality traits and behaviors (Chan \& Yin-Tsuo, 2015). In other words, personality traits, in numerous circumstances, strongly influence the attitudes and behaviors that organizational members demonstrate. In this study, one of the Big Five personality traits i.e. openness to experience, has been focused. Based on the aforementioned assertions, personality traits are correlated with attitude.

Role of openness to experience has already been discussed towards highlighting importance of internal and external environments to people and their readiness to work with new ideas. Among other attributes, one key element is the intellectual curiosity that fosters a person's thrust for learning new things. Such kinds of people always remain in search for opportunities of seeking knowledge. Through the rule of reciprocity, they tend to transfer their own knowledge to others and then gain knowledge from others.

Thus on such basis, hypothesis two is developed:

\section{Hypothesis 2. Openness to experience is positively related to intention to share knowledge.}

According to the Theory of Reasoned Actions, the closest determinant of behavior is intention, which is the cognitive representation of the disposition of an individual to perform a behavior. Intention and behavior are different aspects of a functional relation separated in time and there exists a link between knowledge sharing intention and knowledge sharing behavior $(Z$, 2015). Thus, intention plays a vital role to shape specific behavior of an employee and accordingly, intention to share knowledge has direct effect on knowledge sharing behavior.

Other studies suggest that knowledge sharing behavior of knowledge workers is determined by their intention to share their knowledge. Knowledge sharing behavior refers to the extent to which knowledge workers share their knowledge with their fellow workers (Ajzen, 1991). Intention determines the willingness of an individual to engage in knowledge sharing. In the 
theory of planned behavior, a positive intention equates with a high tendency, willingness, and eagerness towards knowledge sharing. This enables a knowledge exchange environment within the organization wherein each employee develops interest towards knowledge sharing whether tacit or explicit (Alhalhouli, Hassan, \& Der, 2014).

Thus, it has been hypothesized that;

\section{Hypothesis 3. Intention to knowledge sharing positively related to knowledge sharing.}

\section{Moderating role of interpersonal trust on relationship between openness to experience and knowledge sharing}

The influence of interpersonal trust in general and trust in management in particular on knowledge sharing is evident (Renzl, 2008). Trust is viewed as fundamental for the competitiveness of social organizations given the increasedlevels of complexity and uncertainty (Sundaramurthy, 2008). Trust refers to a person's belief that individuals engaged in exchanges will make sincere efforts to uphold their commitments and will not take advantage of the given opportunity; in other words, it is one's willingness to rely on others (Rousseau, Sitkin, Burt \& Camerer, 1998). Mayer et al. (1995) defined interpersonal trust as "the willingness of a party to be vulnerable to the actions of another party based on the expectation that the other will perform a particular action important to the trustor, irrespective of the ability to monitor or control that other party (Lee, Gillespie, Mann, \& Wearing, 2010)'.

Trust is "a psychological state comprising the intention to accept vulnerability based upon the positive expectations of the intentions or behavior of another"'(Evans \& Revelle, 2008). According to Hung, Li and Tse, (2011) We use the term interpersonal trust to refer to the extent of a boundary-spanning agent's trust in her counterpartin the partner organization (Zaheer, McEvily, \& Perrone, 1998).Trust refers to an implicit belief that a partner will not engage in exploitive or opportunistic behaviors.

In this context, Reliance-based trust is defined as a person's willingness to depend on another. Disclosure based trust is defined as a person's willingness to disclose personal or work-related information to another. This two dimensional model of trust draws on earlier work which identified accepting influence and sharing information as behavioral expressions of trust.

Interpersonal trust is regarded as one factor behind peoples' decision to share knowledge. Prior studies found that trust affects workplace attitudes, behaviors, and performance (Dirks \& Ferrin, 2001) Trust can increase the transparency and initiative of inter-organizational learning (Wang, Yeung, \& Zhang, 2011). In this vein, trust has been shown to foster open communication styles, constructive conflict resolution, and free information flow among employees who accepts to communicate more rapidly and in broader scope. This sets foundation for the formal flow of knowledge within the organization. Besides, it also positively influences both efficiency and effectiveness of the knowledge sharing (Muethel, Siebdrat \& Hoegl, 2012).

Hence, hypothesis four is established as:

\section{Hypothesis 4. Interpersonal trust positively moderates the relationship between openness to experience and knowledge sharing.}

\section{THEORETICAL FRAMEWORK}

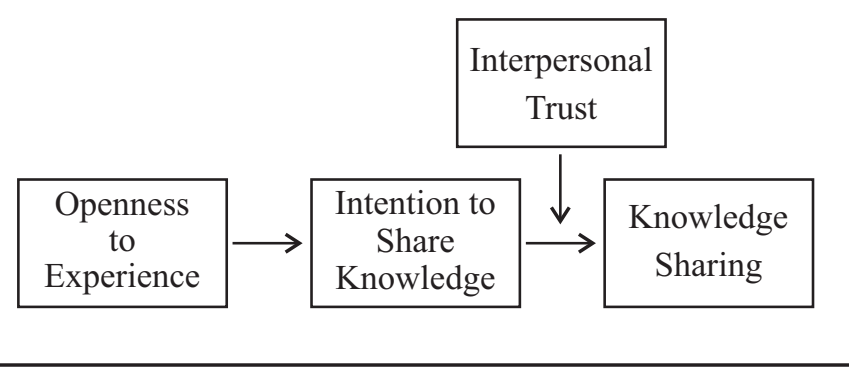

\section{RESEARCH METHODOLOGY}

\section{Sample}

Sample of this study included employees from a public sector organization who were prior assured of confidentiality. Questionnaires were distributed among 250 employees out of which 185 returned after completion. The effective response rate was 74 percent. Female respondents were $15 \%$ of the actual sample. Respondents included employees having diverse educational and professional background. Demographics including age, gender, qualification and experience have been used in this study but control variable has not been decided yet.

\section{INSTRUMENTATION}

\section{Openness to Experience}

Scale adapted by by Flynn, Francis J. (2005), has been used to measure openness to experience (Cronbach's alpha $=0.833$ ) on a 5 point likert scale (1, "strongly disagree," to 5, "strongly agree"). Sample items include "Has an active imagination", "Values artistic, esthetic experiences" and "Is ingenious, a deep thinker". 


\section{Intention to Share Knowledge}

Intention to share knowledge has been measured with the scale adapted by Bock, Gee-Woo, Young-Gul Kim, and Robert W. Zmud (2005) (Cronbach's alpha= 0.774 ) with response scale (1, "strongly disagree," to 5 , "strongly agree"). Sample items include "I will share my work reports and official documents with members of my organization more frequently in the future", "I will always provide my manuals, methodologies and models for members of my organization" and "I intend to share my experience or know-how from work with other organizational members more frequently in the future".

\section{Interpersonal Trust}

Scale adapted by Lee, Heeseok, and Byounggu Choi (2003) has been used to assess interpersonal trust (Cronbach's alpha $=0.860)$ with response scale (1, "strongly disagree," to 5, "strongly agree"). The items include "Our company members are generally trustworthy", "Our company members have reciprocal faith in other members' intentions and behaviors" and "Our company members have reciprocal faith in others' ability".

\section{Knowledge Sharing}

Three items scale by Choi, Sue Young, Heeseok Lee, and YoungjinYoo (2010) has been used to measure knowledge sharing having (Cronbach'salpha $=0.819)$ with response scale. These items include "Our team members share their work reports and official documents with other team members", "Our team members provide their manuals and methodologies for other team members" and "Our team members share their experience or knowhow from work with other team members".

\section{RESULTS}

In order to find support for the direct relationships, mediation and moderation of the proposed model, correlation tests were run on SPSS. Following are the results of the regression analysis:

TABLE 1

Correlation

\begin{tabular}{llllll}
\hline & \multicolumn{1}{c}{ Variables } & \multicolumn{1}{c}{$\mathbf{1}$} & $\mathbf{2}$ & $\mathbf{3}$ & $\mathbf{4}$ \\
\hline 1 & OE & $(0.833)$ & & & \\
2 & INT_SK & .140 & $(0.774)$ & & \\
3 & Trust & $.419^{* *}$ & $.147^{*}$ & $(0.860)$ & \\
4 & K_SHARNG & $.577^{* *}$ & .059 & $.463^{* *}$ & $(0.819)$ \\
**. Correlation is significant at the 0.01 level (2-tailed). \\
*. Correlation is significant at the 0.05 level (2-tailed). \\
\hline
\end{tabular}

Table 1 shows the correlation between the variables. As per the correlation results, Openness to experience are significantly correlated with the trust and knowledge sharing, as discussed above. Likewise, Trust and knowledge sharing are also positively and significantly correlated.

\section{Regression Analysis}

Regression analysis was done using Preacher and Hayes method using PROCESS macro. According to the results, openness to experience positively predicts knowledge sharing as the effect size in the total effect is 0.71 and is significant which means hypothesis one is accepted. Similarly, openness to experience is also significantly associated with the intention to share knowledge having effect size of 0.72 ; hence hypothesis two is also accepted. However, intention to share is not found to be mediating the relationship between openness to experience and knowledge sharing, as there lays a zero value between the upper and lower boot limits of confidence interval, implying that hypothesis three has been rejected.

\section{TABLE 2}

Regression Mediation Analysis

\begin{tabular}{lcccc}
\hline & Effect & SE & LLCI & ULCI \\
\hline Total Effect & 0.7185 & 0.0756 & 0.5694 & 0.8677 \\
Direct Effect & 0.7218 & 0.0765 & 0.5708 & 0.8729 \\
Indirect Effect & -0.0038 & 0.0147 & -0.0502 & 0.0161 \\
\hline
\end{tabular}

Moderation has also been performed through Preacher \& Hayes method. The results clearly show that moderation does not work in relationship between openness to experience and knowledge sharing, because the $\mathrm{R}^{2}$ change of 0.003 is negligible and found to be insignificant, hence, hypothesis four has also been rejected.

TABLE 3

Regression Moderation Analysis

\begin{tabular}{cccc}
\hline & $\boldsymbol{\Delta} \mathbf{R}^{\mathbf{2}}$ & $\mathbf{F}$ & $\mathbf{P}$ \\
\hline Int_1 & 0.0039 & 0.08974 & 0.3448 \\
\hline
\end{tabular}

\section{DISCUSSION AND CONCLUSION}

Purpose to conduct this study was to test relationship between openness to experience and knowledge sharing under the mediating effects of intention to share knowledge and moderating effects of interpersonal trust. According to the findings, hypothesis one has been accepted stating that openness to experience positively predicts knowledge sharing. Similarly, hypothesis two has also been accepted and accordingly validated 
the hypothesis that openness to experience positively predicts intention to share knowledge.

However, impact of intention to share knowledge on knowledge sharing has not been established resulting rejection of hypothesis three. In addition, interpersonal trust could not moderate impact of intention to share knowledge on knowledge sharing. It depicts that hypothesis four has not been accepted. In this context, it may be noted that current study has focused employees of a public sector organization in Pakistan. It is pertinent to mention that majority of Pakistani organizations especially those of public sector lack supportive working environment in terms of trust among employees and their ability/readiness to share their knowledge with coworkers despite having intention. Apparently, this may be logic behind the rejection of hypotheses three and four.

\section{LIMITATIONS AND RECOMMENDATIONS}

In this study, data were collected from a public sector organization which limits the scope of generalizability. Although, the data were collected from various levels of employees within organization, but relatively small sample size hampers the wider generalizability of the results. Similarly, although respondents were provided with maximum familiarity about questions within available time, however, exposure of employees may differ based upon their intellectual as well as working level. This may cause problem in getting desired response within very short period. Hence, lack of proper understanding of questionnaire may be a limitation.

As far as future research direction is concerned, it will be relevant to include other potential areas to be focused such as role of employee's network position towards knowledge sharing. Similarly, it would be interesting to understand the mechanisms that motivate employees to share knowledge withothers such as through different types of relational ties such as horizontal versus vertical ties (e.g., peers versus supervisor-subordinate) and personal friends versus colleagues. Future research also needs to investigate whether there are differences in thetype or quality of knowledge shared when it is considered an in-role versus extra-role behavior.

\section{REFERENCES}

Abrams, L. C., Cross, R., Lesser, E., \& Levin, D. Z. (2003). Nurturing interpersonal trust in knowledgesharing networks. The Academy of Management Executive, 17(4), 64-77.

Alajmi, B. M. (2011). The intention to share: professionals' knowledge sharing behaviors in online communities (Doctoral dissertation, Rutgers
University-Graduate School-New Brunswick).

Al-Ajmi, J., \& Abo Hussain, H. (2011). Corporate dividends decisions: evidence from Saudi Arabia. The Journal of Risk Finance, 12(1), 41-56.

Alhalhouli, Z. T., Hassan, Z. B., \& Der, C. S. (2014). Factors affecting knowledge sharing behavior among stakeholders in Jordanian hospitals using social networks. International Journal of Computer and Information Technology, 3(5), 919-928.

Asrar-ul-Haq, M., \& Anwar, S. (2016). A systematic review of knowledge management and knowledge sharing: Trends, issues, and challenges. Cogent Business \& Management, 3(1), 1127744.

Bakker, M., Leenders, R. T. A., Gabbay, S. M., Kratzer, J., \& Van Engelen, J. M. (2006). Is trust really social capital? Knowledge sharing in product development projects. The Learning Organization, 13(6), 594-605.

Blankenship, S. S., \&Ruona, W. (2009). Exploring knowledge sharing in social structures: Potential contributions to an overall knowledge management strategy. Advances in Developing Human Resources, 11, 290-306.

Bordia, P., Irmer, B. E., \& Abusah, D. (2006). Differences in sharing knowledge interpersonally and via databases: The role of evaluation apprehension and perceived benefits. European Journal of Work and Organizational Psychology, 15(3), 262-280.

Butler, B. S. (2001). Membership size, communication activity, and sustainability: A resource-based model of online social structures. Information Systems Research, 12(4), 346-362.

Cabrera, A., Collins, W. C., \& Salgado, J. F. (2006). Determinants of individual engagement in knowledge sharing. The International Journal of Human Resource Management, 17(2), 245-264.

Carmeli, A., Gelbard, R., \& Reiter-Palmon, R. (2013). Leadership, Creative Problem-Solving Capacity, and Creative Performance: The Importance of KnowledgeSharing.HumanResourceManagement, 52(1), 95-121

Chan, S. H., \& Yin-Tsuo, H. (2015). I Exploring the Knowledge-Sharing Intention of Research and Development Personnel in the Electronics Industry. IJEIR, 4(1), 40-44.

Chan, S. H., \& Yin-Tsuo, H. (2015). I Exploring the Knowledge-Sharing Intention of Research and Development Personnel in the Electronics Industry. IJEIR, 4(1), 40-44.

Cheung, F. M., Shu Fai Cheung, Jianxin Zhang, Leung, K., Leong, F., \&KuangHuiyeh. (2008). Relevance of Openness as a Personality Dimension in Chinese Culture: Aspects of its Cultural Relevance. Journal of Cross-Cultural Psychology, 39(1), 81-108. 
http://doi.org/10.1177/0022022107311968

Constant, D., Sproull, L., \& Kiesler, S. (1996). The kindness of strangers: The usefulness of electronic weak ties for technical advice. Organization Science, 7(2), 119-135.

Cooper R (2001), Winning at New Products, Perseus Publishing, New York.

Costa, P. T., \& McCrae, R. R. (1992). Normal personality assessment in clinical practice: The NEO Personality Inventory. Psychological Assessment, 4(1), 5.

Cox, T. H., Lobel, S. A., \& McLeod, P. L. (1991). Effects of ethnic group cultural differences on cooperative and competitive behavior on a group task. Academy of Management Journal, 34(4), 827-847.

Crossan, M. M., Lane, H. W., \& White, R. E. (1999). An organizational learning framework: From intuition to institution. Academy of Management Review, 24(3), 522-537.

Dirks, K. T., \& Ferrin, D. L. (2001). The role of trust in organizational settings. Organization Science, 12(4), 450-467.

Evans, A. M., \&Revelle, W. (2008). Survey and behavioral measurements of interpersonal trust. Journal of Research in Personality, 42(6), 15851593.

Fishbein, M., \& Ajzen, I. (1977). Belief, attitude, intention, and behavior: An introduction to theory and research.

Fishbein, M., \& Ajzen, I. (1975). Belief, attitude, intention and behavior: An introduction to theory and research. Reading, MA: Addison-Wesley.

Foss, N. J., \& Pedersen, T. (2002). Transferring knowledge in MNCs: The role of sources of subsidiary knowledge and organizational context. Journal of International Management, 8(1), 49-67.

Hülsheger, U. R., Anderson, N., \& Salgado, J. F. (2009). Team-level predictors of innovation at work: a comprehensive meta-analysis spanning three decades of research. Journal of Applied Psychology, 94(5), 1128.

Hung, K., Li, S. Y., \&Tse, D. K. (2011). Interpersonal Trust and Platform Credibility in a Chinese Multibrand Online Community. Journal of Advertising, 40(3), 99-112.

Ajzen, I. (1991). The theory of planned behavior. Organizational Behavior and Human Processes, 50, 179-211.

Ipe, M. (2003). Knowledge sharing in organizations: A conceptual framework. Human Resource Development Review, 2(4), 337-359.

Jackson, S. E., Chuang, C. H., Harden, E. E., Jiang, Y., \& Joseph, J. M. (2006). Toward developing human resource management systems for knowledgeintensive teamwork. Research in Personnel and
Human Resources Management, 25(6), 27-70.

Lee, P., Gillespie, N., Mann, L., \& Wearing, A. (2010). Leadership and trust: Their effect on knowledge sharing and team performance. Management Learning, 41(4), 473-491.

LePine, J. A. (2003). Team adaptation and postchange performance: effects of team composition in terms of members' cognitive ability and personality. Journal of Applied Psychology, 88(1), 27.

Li, X., Montazemi, A. R., \& Yuan, Y. (2006). Agentbased buddy-finding methodology for knowledge sharing. Information \& Management, 43(3), 283296.

Matzler, K., Renzl, B., Müller, J., Herting, S., \&Mooradian, T. A. (2008). Personality traits and knowledge sharing. Journal of Economic Psychology, 29(3), 301-313.

Mayer, R. C., Davis, J. H., \& Schoorman, F. D. (1995). An integrative model of organizational trust. Academy of Management Review, 20(3), 709-734.

McCrae, R. R., \& Costa, P. T. (1987). Validation of the five-factor model of personality across instruments and observers. Journal of Personality and Social Psychology, 52(1), 81.

McElroy, M.W. (2003), The New Knowledge Management; Complexity, Learning, and Sustainable Innovation, Butterworth-Heinemann, New York, NY.

McNeish, J., \& Mann, I. J. S. (2010). Knowledge sharing and trust in organizations. IUP Journal of Knowledge Management, 8(1/2), 18.

Mooradian, T., Renzl, B., \& Matzler, K. (2006). Who trusts? Personality, trust and knowledge sharing. Management Learning, 37(4), 523-540.

Muethel, M., Siebdrat, F., \& Hoegl, M. (2012). When do we really need interpersonal trust in globally dispersed new product development teams?. $R \& D$ Management, 42(1), 31-46.

Renzl, B. (2008). Trust in management and knowledge sharing: The mediating effects of fear and knowledge documentation. Omega, 36(2), 206-220.

Rousseau, D. M., Sitkin, S. B., Burt, R. S., \& Camerer, C. (1998). Not so different after all: A cross-discipline view of trust. Academy of Management Review, 23(3), 393-404.

Shim, J. (2010). The relationship between workplace incivility and the intention to share knowledge: The moderating effects of collaborative climate and personality traits (Doctoral dissertation, University of Minnesota).

Silvia, P. J., Nusbaum, E. C., Berg, C., Martin, C., \& O'Connor, A. (2009). Openness to experience, plasticity, and creativity: Exploring lower-order, high-order, and interactive effects. Journal of 
Research in Personality, 43(6), 1087-1090.

Silvia, P. J., Winterstein, B. P., Willse, J. T., Barona, C. M., Cram, J. T., Hess, K. I., ... \& Richard, C. A. (2008). Assessing creativity with divergent thinking tasks: Exploring the reliability and validity of new subjective scoring methods. Psychology of Aesthetics, Creativity, and the Arts, 2(2), 68.

Srivastava, A., Bartol, K. M., \& Locke, E. A. (2006). Empowering leadership in management teams: Effects on knowledge sharing, efficacy, and performance. Academy of Management Journal, 49(6), 1239-1251.

Sundaramurthy, C. (2008). Sustaining trust within family businesses. Family Business Review, 21(1), 89-102.

Swan, J., Newell, S., Scarbrough, H., \& Hislop, D. (1999). Knowledge management and innovation: networks and networking. Journal of Knowledge Management, 3(4), 262-275.

Tiwana A (2002), The Knowledge Toolkit, Pearson, Upper Saddle River, New Jersey.

Van Knippenberg, D., De Dreu, C. K., \& Homan, A. C. (2004). Work group diversity and group performance: an integrative model and research agenda. Journal of Applied Psychology, 89(6), 1008-11022.

Wampold, B. E., \& Imel, Z. E. (2015). The great psychotherapy debate: The evidence for what makes psychotherapy work. Routledge.
Wang, L., Yeung, J. H. Y., \& Zhang, M. (2011). The impact of trust and contract on innovation performance: The moderating role of environmental uncertainty. International Journal of Production Economics, 134(1), 114-122.

Wang, S., \& Noe, R. A. (2010). Knowledge sharing: A review and directions for future research. Human Resource Management Review,20(2), 115-131.

Wasko, M. M., \&Faraj, S. (2000). "It is what one does": why people participate and help others in electronic communities of practice. The Journal of Strategic Information Systems, 9(2), 155-173.

Witherspoon, C. L., Bergner, J., Cockrell, C., \& Stone, D. N. (2013). Antecedents of organizational knowledge sharing: a meta-analysis and critique. Journal of Knowledge Management, 17(2), 250277.

Yoo, Y., \& Torrey, B. (2002). National culture and knowledge management in a global learning organization. The strategic management of intellectual capital and organizational knowledge, 421-434.

Z, D. I. C. (2015). Knowledge sharing: the role of psychological variables in leaders and collaborators. Suma Psicológica, 22(1), 63-69.

Zaheer, A., McEvily, B., \& Perrone, V. (1998). Does Trust Matter? Exploring the Effects of Interorganizational andInterpersonal TrustonPerformance.Organization Science, 9(2), 141-159. 